\title{
The Role of ICTs in Climate Change Adaptation: A Case of Small Scale Farmers in Chinsali District
}

\author{
Kashale Chimanga ${ }^{1}$, Kennedy Kanja ${ }^{2}$ \\ ${ }^{1}$ Department of ICT, School of Information and Communication Technology, Copperbelt University, Kapasa Makasa Campus, Chinsali, \\ Zambia \\ ${ }^{2}$ Department of Agriculture and Aquaculture, School of Natural Resources, Copperbelt University, Kapasa Makasa University Campus, \\ Chinsali, Zambia
}

\section{Email address:}

kashalechimanga@gmail.com (K. Chimanga),kennedy2006@yahoo.com (K. Kanja)

\section{To cite this article:}

Kashale Chimanga, Kennedy Kanja. The Role of ICTs in Climate Change Adaptation: A Case of Small Scale Farmers in Chinsali District. Mathematics and Computer Science. Vol. 5, No. 6, 2020, pp. 103-109. doi: 10.11648/j.mcs.20200506.11

Received: July 3, 2020; Accepted: July 27, 2020; Published: December 11, 2020

\begin{abstract}
The purpose of this study was to determine the role of ICT in climate change adaptation by the small scale farmers in Chinsali district of Muchinga province. To this effect, a descriptive survey was conducted on a sample of 278 randomly selected small scale farmers, out of an estimated population of 1000 in Chinsali main farming block. Out of the 278 questionnaires, 267 were successfully filled and returned. The results were tested for reliability and normality. According to the results, small scale farmers in this area lack information about climate change and this make it difficult for them to adapt to its effects. The study also establish that, using ICTs to create awareness, provide access to climate change information as well as capacity building in the use of various ICTs to identify the effects of climate change can help these farmers to adapt to its effects. Based on this, the study recommended that deliberate policies should be put in place to ensure that ICT services such as the internet, mobile networks and SMS are widely used in disseminating information about climate adaption to small scale farmers in the district. It was also recommended that handheld device such as mobile phones and PDAs which most of these farmers have access to should be used to sensitize them about the effect of climate change and how to adapt to it. The study further recommended that building adaptive capacity, such as on ICT-enabled interventions in the agriculture sector, should be spearheaded to enhance adaptation to climate change. It was further recommended that government should build adaptive capacity, such as on ICT-enabled interventions in the water and agriculture sectors, on weather prospects and water hazards, land management and adaptive capacity of small scale farmers among other recommendations.
\end{abstract}

Keywords: ICTs, Agriculture, Climate Change, Adaptation, Rainfall, Farming, Rural Population

\section{Introduction}

Zambia has in the recent past experienced a down turn in its economic growth which is attributed to climate change. Climate changes includes global warming, changing weather pattern, heavy monsoon, unexpected rain fall, rapid urbanization, pollution and industrialization, losses of crop due to drought, glacier melting resulting rises water level in rivers and this phenomenon is the consequences of flash flood [1]. Climate changes impose impacts on environment as well as human activities.

The most hit sectors include the agriculture and the energy. Since Agriculture in Zambia accounts for 18-20 percent of the country's gross domestic product and employs approximately two-thirds of the country's labour force, the poor performance of this sector leaves much to be desired. Agriculture in Zambia is a key source of livelihoods for 50 percent of the country [1]. Approximately 12 percent of total land area is suitable for arable use and over 80 percent of the country's farmers are subsistence farmers. Most of the country's farms, located in central, south, and southwestern Zambia, have become increasingly prone to drought and have received low, unpredictable, and unevenly distributed rainfall.

The 2018/2019 farming season in particular saw a lot of small scale farmers records the lowest yield ever due to lack of information about the drought that occurred. The farmer failed to identify the type of crops which are drought resistance and has the potential to grow in particular areas 
[2]. As a results most areas of the country, particularly the Southern, Western and parts of the central provinces were badly hit and there is looming hunger in these areas. Climate change in Zambia is real and if measures are not taken to sensitize the general public, and more especially the small scale farmers on the impact, adaptation maybe difficult to attain.

Information and Communication Technology can play a pivotal role in monitoring, mitigation and adaptation of Climate changes challenges. ICTs are enabling tools if integrated strategically into the agriculture sector can improve efficiency and effectiveness of efforts in climate change mitigation and adaptation by small scale farmers [3]. ICT has the potential to help vulnerable community to reduce the risk related to climate changes through education and awareness at lowest level of community by sharing practical and theoretical knowledge, empowering community to access the knowledge and relevant information applicable locally to save lives [3].

ICTs have the potential to inform and enhance the processes for formulating policies and making decision towards the achievement of climate change adaptation goals set by governments to help the communities that are mostly hit and do not have access to information to make informed decisions [4].

It's against this background that this study was conducted to establish the role of ICTs in Climate Change Adaptation in Zambia's Agriculture Sector.

\subsection{Problem Statement}

In Zambia, Agriculture is the cornerstone of many livelihoods and the changes in the climate experienced in the 20119/2019 farming season has greatly affected the majority of people more especially those in rural parts of the country [6]. The country is currently experiencing hunger in some regions that experienced crop failure due to changes in the climatic condition [6]. People in these areas lack information about the effect of climate change and as a result fail to make informed decision as to which crops to grow that are draught resistant. This has in the process increase the poverty level in these areas.

According to the Central Statistics [7] the rural poverty levels is hovering around $83 \%$ and that any further negative shift due to climate change factors will spell doom to the country in general, but particularly to the rural based populations that entirely depend on agriculture for survival.

Most rural population in Zambia lack information to help them make informed decisions about climate change adaptation. Access to Information and Communication Technologies (ICTs) can be very beneficial to mitigate this problem. With regards to farming information, the rural population can take advantage of the increased advancement in Information and Communication Technologies (ICTs) to provide them with information about draught resistance crop cultivation, best agricultural practice, farmer welfare program and weather forecast [7] thereby helping them to adapt to climatic changes. If well implemented, ICT can play an important role in monitoring and tracking climate changes and thereby allowing the small scale farmers to adapt to changes in the climate easily. It is based on this background that the study was conducted to determine the role of ICTs in climate change adaptation by small scale farmers in Chinsali district of Muchinga province.

\subsection{Objectives of the Study}

The objectives of the study included the following:

To determine the role of ICTs in climate change adaptation.

To establish whether creating awareness about climate change adaptation through the use of ICTs can help farmers to successfully adapt to climate change.

To suggest the measures that can be put in place to ensure a successful adaption to climate change by small scale farmers in the district.

\subsection{Research Question}

From the objectives above, the following research questions were derived:

What is the role of ICTs in climate change adaptation by small scale farmers in Chinsali district?

To what extent can creating awareness about climate change adaptation through the use of ICTs help farmers to successfully adapt to climate change?

What measures should be put in place to ensure a successful adaption to climate change by small scale farmers in Chinsali district?

\subsection{Significance of the Study}

The findings of this study have the potential to help small scale farmers in Zambia understand the effects of climate change and take necessary measures to adapt to it through the use of ICTs available. In addition, the study provide adequate information about the role of ICT in climate change adaption and how embracing these technologies can help farmers to plan the season without challenges. The study will also contribute to the existing literature on ICTs and climate change.

\subsection{Limitations of the Study}

It would have been better to consider the whole country, particularly those mostly hit by the effects of climate changes, however due to limited resource; the focus was limited to Chinsali District of Muchinga province. The study was limited to the use of mobile phone technologies in disseminating information with regards to crop cultivation, best agricultural practice, farmer welfare program, day to day rainfall pattern information and weather forecast.

\subsection{Justification of the Study}

Chinsali district was chosen for this study because one of the researchers themselves is small scale farmers and lives in this part of the country. In addition, the effects of climate 
change are being felt everywhere across the country and Chinsali district in Muchinga province is not an exception.

\section{Review of Literature}

The effects of climate change have been a wide research topic with many solutions coming across. Globally, ICTs play a very crucial role to lessen the various impact of climate change particularly in adaptation and mitigation through exchanging and transferring knowledge and information. People of many developed and developing countries are using ICT services in agriculture, health, early warning, and disaster risk reduction sectors [8]. As for example, India has developed Internet portal to provide online agro-met advice and to provide related information to the farmers about the effect of climate change with a particular focus on mitigation.

IPCC, the Intergovernmental Panel for Climate Change, have also stressed the ability of decision-makers to manage information as an important factor determining the chance for a community to adapt to climate change. This is one of the reason why the Information and Communication Technologies (ICT) can play an important role in this challenge [15].

In Africa, most countries have identified many new applications of ICTs to adapt to the effect of climate change. In Uganda for instance, Community Knowledge Workers (CKWs) network has been developed which acts as the center for disseminating information to community farmers. On the other hand, Malawi has introduced a communitybased Participatory Geographic Information Systems (PGIS) Program to build a centrally located model which can be used to determine current and future water needs [22]. In Zimbabwe, ICT services are widely used for early warning systems, urban and rural planning, health services, and education [8].

Kenya and Zambia are using ICT services for early warning in different ways, providing weather-related press releases and transferring information through interaction with media personnel as well as public service announcements through radio and TV channels, Internet and Mobile Apps [10].

For instance, in Brazil, a study was conducted on the importance of role of ICT in monitoring climate changes [2]. Increasing level of Green House Gasses (GHG) is one of the main sources of climate changes of the planet. Most of the GHG emission in Brazil is due to electricity generation and industrial production. Deforestation is one of the major causes of increasing GHG emission along with above mentioned causes.

In India the study conducted established that Climate of the Adi tribal region is very hard, frequent climate changes directly impacts on agricultural sector [3]. To help the poor farmers and to support the agricultural sector in tribal area ICT based project eArik (eagriculture) was initiated in 2007. The purpose of this project was to share the climate smart agricultural practices among the farmers plus food security. A knowledge center equipped with digital devices like Computer, printer, scanner, internet, TV and phone, was established in the community.

The study conducted in Latin America [5] established that, changes in water quantity and quality due to climate change are expected to affect the availability of and access to food. In terms of information dissemination, the country have used ICTs to share strategies developed by local communities to address the effects of climate change on food security. The programmes produced by community radios in Africa.

Looking at the climate change adaptation sector, it is possible to apply the three main functions of ICTs to the development of an adaptation strategy in a specific community.

First, data collection is important to constantly monitor the status of the Earth climate system. Second, it is essential to have tools for processing data and information that can guide the stakeholders in the analysis, planning and implementation of possible adaptation strategies. And thirdly, communication tools are needed to manage the adaptation process and build on the knowledge which is generated in order to strengthen capacities and relationships among the stakeholders within and outside the given system [14].

Southern African region including Zambia has experienced negative impacts associated with climate change especially in the recent past decades where extreme events such as droughts and floods and their severity have occurred more frequent than usual compared to past similar length of periods [4]. There is also a notable associated reduction in precipitation as a result of extreme droughts.

Zambia's agriculture sector is already experiencing the negative impacts of climate change with severe effects predicted by Climate Change Models showing more frequent extreme events such as droughts and floods in some areas but with a general decreasing precipitation in the Southern parts of the country which will result in shortened crop growing seasons and increased evapotranspiration rates resulting in crop failure or reduced yields of main staple maize crop [7].

Other studies established that most rural communities are dependent on agriculture for their livelihood. Agriculture is an important sector, both in the formal economy and in sustaining local livelihoods [24]. Many factors affect smallholder agriculture. These include climate change and climate variability, population increase, environmental degradation, poor infrastructure, poor market access and lack of access to information and resources [25]. Hence the need to investigate the role of ICT in the climate change adaptation is key.

\section{Knowledge Gap}

As can be observed from the above literature, the application of ICTs in climate change adaptation by small scale farmers in rural areas is still missing to a large extent. As observed by many researchers, the application of Information and Communication Technologies in the field of climate change is unanimously invoked by experts and 
institutions, who recognize the technologies as an effective mean to fight climate change. It is based on this background that this study was conducted bearing in mind that ICTs has the potential to offer solutions to this problem.

\section{Conceptual Model}

From the literature review above, the following model depicted as Figure 1 was adopted for this study. The model below depict ICT as an intervening variable, which can help in creating climate change awareness, provide the relevant information on climate change as well as enhancing capacity building to small scale farmers to use ICTs in climate change adaptation.

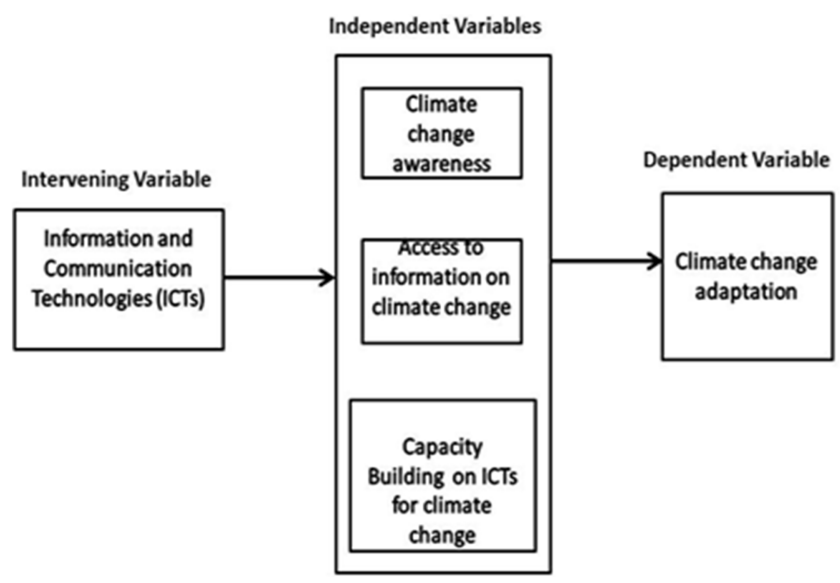

Figure 1. Conceptual Model.

\section{Research Methodology}

This section explains the research design used in the study, the population and sample, data collection, treatment of the experiment and statistical analysis techniques applied in the study.

\subsection{Research Design}

The study utilized a descriptive survey design to identify, analyze and describe the role of ICTs on climate change adaption by small scale farmers in Chinsali district of Muchinga province. A descriptive survey describes and interprets "what is" and is concerned with conditions or relationships that exist; practices that prevail on the ground. This design was chosen because the results gave definite conclusions and it described the characteristics of the respondents who in this case happened to be small scale farmers in the district.

\subsection{Population and Sample Size}

Chinsali district main agriculture camp has an estimated population of 1000 farmers who belong to different cooperative groups. Out of this population, a sample of 278 respondents was randomly selected to take part in the study. All the 278 sampled respondents were administered with questionnaires to get their views on the topic of the study. Out of the 278 questionnaires distributed, 267 were successfully filled and returned representing $96 \%$ of the total response rate which the researchers found necessary to proceed with the data analysis.

\subsection{Instruments for Data Collection}

The instruments for data collection included the questionnaires that was specifically design to fit the level of the small scale farmers participants.

\subsection{Data Analysis}

The data collected were analyzed and coded using the statistical package for social sciences (SPSS) version 2.0 software. The SPSS is a windows based program that can be used to perform data entry and analysis; and to create tables and graphs among other things. The results were tested for reliability and then presented using the mean values.

\section{Results Presentation and Analysis}

The reliability of the data collected was investigated using Cronbach's alpha. Cronbach's alpha's values for the variables considered in the study are presented in Table below. Three variables were under consideration in this study; these include; climate change awareness through the use of ICTs, access to climate change information and capacity building in using ICTs in climate change adaption. The Cronbach's scores for the three variables were $0.772,0.895$ and 0.908 respectively.

Table 1. Reliability, normality and mean

\begin{tabular}{|c|c|c|c|c|}
\hline \multirow{2}{*}{ Variable } & \multicolumn{4}{|c|}{ Z-values } \\
\hline & Mean Score & $\mathbf{A}$ & Skewness & Kurtosis \\
\hline Awareness & 5.219 & 0.896 & -0.1540 & 0.618 \\
\hline Access to information & 4.181 & 0.793 & -0.380 & 1.584 \\
\hline Capacity building & 4.613 & 0.907 & -0.441 & 1.243 \\
\hline Climate change Adaptation & 5.372 & 0.916 & -0.660 & 1.195 \\
\hline
\end{tabular}

According to the results depicted in Table, the internal consistence of the three variables under investigations was $0.896,0.793$ and 0.907 . The results shows that all the variables, climate change awareness, access to information on climate change and capacity building in using the ICTs in climate change are considered reliable as their Cronbach's values were all above 0.70 . This implies that, these variables are suitable enough to determine the role of ICT in climate change adaptation by small scale farmers in Chinsali district of Muchinga province. 
Table 2. Pearson correlation $(n=80)$.

\begin{tabular}{lll}
\hline Variables & Sig. & CC adaptation \\
\hline Climate change awareness & $\mathrm{r}$ & 0.664 \\
& Sig. (1-tailed) & 0.000 \\
Access to information & $\mathrm{r}$ & 0.320 \\
& Sig. (1-tailed) & 0.022 \\
Capacity building & $\mathrm{r}$ & 0.304 \\
\end{tabular}

Sig.(1-tailed) at $95 \%$ Confidence level.

\section{CC-climate change}

At the same time, to ensure the validity of the correlation, the normality test was conducted using the skewness and kurtosis Z-values as depicted in Table above. According to the results showed in the table on each variable, the $\mathrm{Z}$-values are within the range of -1.96 and +1.96 . This shows that all the variables involved in the study are considered normally distributed.

Table 3. Regression Analysis.

\begin{tabular}{lllll}
\hline Model & R & R Square & Adjusted R Square & Std. Error of the Estimate \\
\hline 1 & $.701 \mathrm{a}$ & 0.563 & 0.542 & 0.6285 \\
\hline
\end{tabular}

a. Predictors: (Constant), climate change awareness, access to information and capacity building.

b. Dependent Variable: climate change adaptation.

\section{Results Discussion}

The purpose of this study was to assess the role of ICTs in Climate Change Adaptation. According to the results depicted in Table 1 above, the mean values of all the three variables climate change awareness, access to climate change information and capacity building in using ICTs in climate change adaption are 5.219, 4.181, 4.613 and 5.372 respectively. According to the results obtained, it was observed that the majority of the respondents indicated that they lack information about the climate change and this makes it difficult for them to adapt to its effects. This is in line with the study by Kempton [11] who established that changes in the climate where the farmers lack awareness and general understanding of climate change, and the technical knowhow of how to enhance the productivity of their rainfed agriculture. Kempton [11] stresses that there is need for people to have detailed knowledge of climate change to help them form opinions on the issue.

In the same manner the study sought to determine whether or not access to information about climate change affects its adaptation by the majority of the small scale farmers $(\mathrm{M}=4.181)$. This means that the small scare farmers in the district lack access to information about climate change. According to Duncombe [12] there are many sources in which access to information can be obtained. Mainly through ICTs devices. These include telephony, television and radio. Access device technologies represent the interface through which users' access information and communications services such as mobile phones, desktop personal computers and handheld devices such as laptops and tablets.

The other variable considered was whether or not capacity building to use ICTs devices to disseminate information about climate change can help the small scale farmers adapt to the effects of the climate change. The mean value obtained was 4.613 indicating that most respondents agreed that when trained to use ICTs, it will be easier for them to adapt to climate changes and its effect. The findings correlates with that conducted in India [5] which revealed that, in terms of information dissemination, the country have used ICTs to share strategies developed by local communities to address the effects of climate change on food security.

In the same manner, regression analysis was carried out on the data and the results are depicted in Table 3 above. The results in this table show that the factors under this study which were observed to hinder climate change adaptation by small scale farmers explain only $56.3 \%$ of the total adaptation to climate change as represented by the R2. This means that the three independent variables (awareness, access to information and capacity building) only contribute about $56.3 \%$ to climate change adaptation whereas other factors not considered in this study only contribute about $44.7 \%$ to climate change adaptation.

\section{Conclusion}

The objective of this study was to determine the role of ICT in climate change adaptation by the small scale farmers in Chinsali district of Muchinga province. To this effect, a descriptive survey was conducted on 278 randomly selected small scale farmers to understand their level of adaptation to climate change. According to the results, it was revealed that lack of awareness about the effect of climate change make it difficult for the farmers to adapt to its effects. The study also established that they lacked access to information that that would enable them to successfully adapt to the effect of climate change. Around half of the respondents indicated that they did not 
get information on the likely rainfall amount and distribution in the coming season because access to this information is not available. The study revealed that there is a huge information deficit amongst these farmers, which in turn limits their adaptive capacity to respond to climate change. With regards to capacity building, it was revealed that, the use of ICTs and capacity building in this knowledge domain can help the small scale farmers in adapting to climate change. Hence, in order to realise their great potential, the strategic use of ICTs can enhance the efficiency and effectiveness of climate change adaptation programmes among the small scale farmers in Chinsali district of Muchinga province.

\section{Recommendations}

Based on the discussion and conclusions, the following recommendations are made:

That deliberate policies should be put in place to ensure that ICT services such as the internet, mobile networks and SMS are widely used in disseminating information about climate adaption to small scale farmers in the district.

That handheld device such as mobile phones and PDAs which most of these farmers have access to should be used to sensitize them about the effect of climate change and how to adapt to it.

That building adaptive capacity, such as on ICT-enabled interventions in the agriculture sector, should be spearheaded to enhance adaptation to climate change.

Building the capacity for integrating ICTs into adaptation policy development will have significant benefits.

That government should build adaptive capacity, such as on ICT-enabled interventions in the water and agriculture sectors, on weather prospects and water hazards, land management and adaptive capacity of small scale farmers.

\section{Areas of Further Research}

Considering the fact that this is the first study to look at the role of ICTs in climate change adaption by small scale farmers in Chinsali district of Muchinga province, there is more study that is needed to be done in the following areas:

A study to determine the use of ICTs in providing real time information about the weather changes.

A similar study should be conducted using other ICT tools such as cell phones and web applications.

\section{Acknowledgements}

The authors are so grateful to those small scale farmers who took time, out of their busy schedules to participate in the study. The researchers also wish to acknowledge and sincerely thank the Management of the Copperbelt University, Kapasa Makasa campus for providing a conducive environment for young researchers to do research without any interference.

\section{References}

[1] Nelson, D. R., Adger, N. W. and Brown, K. (2007) Adaptation to Environmental Change: Contributions of a Resilience Framework, Annual Review of Environment and Resources, 32, p. 395-419.

[2] Ptrick P. Kalas, Planting the Knowledge Seed Adapting to climate change using ICTs Concepts, current knowledge and innovative examples, Building Communication Opportunities (BCO) Alliance, (2009).

[3] Jianhua S., Xu Y., and Yu W, Solar Wireless Intelligent Online Hydrological Monitoring System, In Info. Tech. and App. (IFITA), International Forum on, 280-282, IEEE (2010).

[4] Niyibizi A. and Komakech A, Climate Change Mitigation in Developing Countries Using ICT as an Enabling Tool, In Climate-Smart Technologies (pp. 19-32), Springer Berlin Heidelberg, (2013).

[5] DFID. (2002). Department for International Development Zambia Agriculture Dataset. An assessment of trends in the Zambian Agriculture Sector, December, 2002.

[6] www.theIDLgroup.com.

[7] Rajão R., ICT Based Monitoring of Climate Change Related Deforestation: The Case of INPE in the Brazilian Amazon, Climate Change, Innovation and ICTs Project Case Studies, Centre for Development Informatics, University of Manchester, UK http://www. niccd. org., (2012).

[8] NAPA. (2007). The National Adaptation Programme of Action (NAPA), Ministry of Tourism, Environment, and Natural Resources, Zambia.

[9] Molly E. Brown, Christopher C. Funk, 2008: Food Security Under Climate Change. Science; Vol. 319, no. 5863, pp. 580581 .

[10] David B. Lobell, Marshall B. Burke, Claudia Tebaldi, Michael D. Mastrandrea, Walter P. Falcon, and Rosamond L. Naylor, 2008: Prioritizing Climate Change Adaptation Needs for Food Security in 2030. Science; Vol. 319, no. 5863, pp. 607-610.

[11] J. Bruinsma (editor), 2003: "World Agriculture: Towards 2015/2030 - An FAO Perspective". Earthscan Publications Ltd, London.

[12] Phiri, James S. (2009). Zambia Environment Water And Sanitation Linkages, Kanyama And Chazanga Peri-Urban Areas Of Lusaka, Zambia. Water And Sanitation For Urban Poor (Wsup) Wsup Project Report 2009.

[13] Zambia Metereology Department (2013). Rainfall and temperature Data (1950-2010).

[14] Balaji, V. \& Craufurd, P. (2011). Using information and communication technologies to disseminate and exchange agriculture-related climate information in the Indo Gangetic Plains, CCAFS Project Report, CGIAR Research Program on Climate Change, Agriculture and Food Security (CCAFS).

[15] Sala, S. 2009. Information and communication technologies for climate changeadaptation, with a focus on the agricultural sector. Thinkpiece for CGIAR Science Forum Workshop on "ICTs transforming agricultural science, research and technology generation," Wageningen, Netherlands. 
[16] IPCC, 2001: “Climate Change 2001: Impacts, Adaptation \& Vulnerability Contribution of Working Group II to the Third Assessment Report of the Intergovernmental Panel on Climate Change (IPCC)". Cambridge University Press, UK. James J. McCarthy, Osvaldo F. Canziani, Neil A. Leary, David J. Dokken and Kasey S. White (Eds.).

[17] Labelle, R., Rodschat, R. \& Vetter, T. (2008) ICTs for e-Environment: Guidelines for Developing Countries with a Focus on Climate Change. International Telecommunication Union (ITU), Geneva. http://www.itu.int/ITU-D/cyb/app/docs/itu-icts-for-e-environm ent.pdf.

[18] MacLean, D. (2008) ICTs, Adaptation to Climate Change, and Sustainable Development at the Edges. International.

[19] Telecommunication Union Symposium on ICTs and Climate Change. London: International Institute for Sustainable Development.

[20] Mungai, W. (2005) 'Using ICTs for Poverty Reduction and Environmental Protection in Kenya: The "M-vironment" Approach', in: A Developing Connection: Bridging the Policy Gap between the Information Society and Sustainable
Development. IISD. Winnipeg, 43-76. http://www.iisd.org/pdf/2005/networks_dev_connection_keny a.pdf.

[21] OECD. (2009) Integrating Climate Change Adaptation into Development Co-operation: Policy Guidance, Organisation for Economic Co-operation and Development. http://www.oecd.org/dataoecd/0/9/43652123.pdf.

[22] Ospina, A. V. \& Heeks, R. (2010) Linking ICTs and Climate Change Adaptation: A Conceptual Framework for e-Resilience and e- Adaptation. Centre for Development Informatics, University of Manchester, http://www.niccd.org/ConceptualPaper.pdf.

[23] http://www.raosoft.com/samplesize.html. Accessed on 13/10/2019 at 10:00 PM.

[24] Vogel, C. 2005. "Seven Fat Years and Seven Lean Years"? Climate Change and Agriculture in Africa. IDS Bulletin 36 (2).

[25] Morton, J. F. 2007. The impact of climate change on smallholder and subsistence agriculture.. PNAS 104 (50): 19680-19685. 